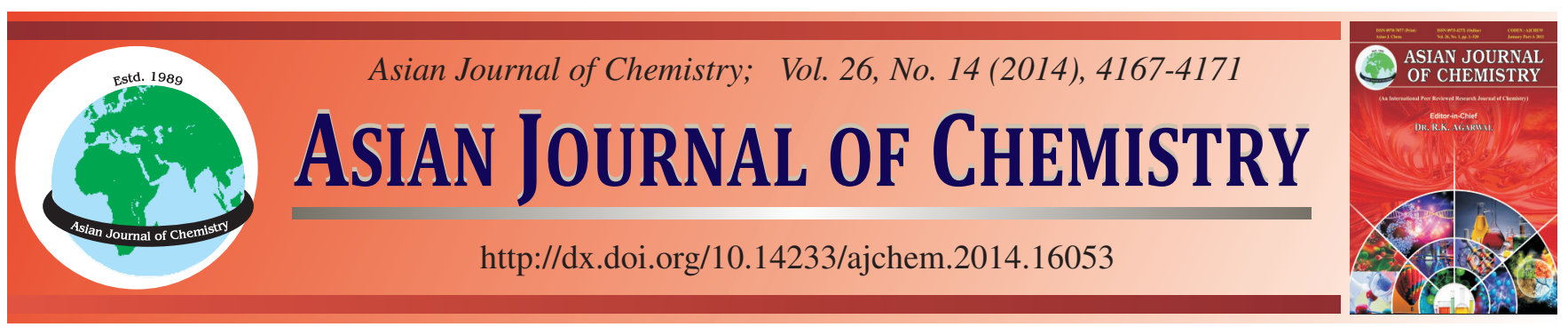

\title{
Characterization of Magnetic Metal Encapsulated in Multi-Walled Carbon Nanotubes Synthesized from Methyl Ester of Pongamia pinnata Oil and Its Application for Removal of Arsenic Ions from Aqueous Solution
}

\author{
P. Mahalingam ${ }^{1}$, N. Sivakumar ${ }^{2}$, M. Karthik ${ }^{3}$ and S. Karthikeyan ${ }^{2, *}$
}

${ }^{1}$ Department of Chemistry, Arignar Anna Government Arts College, Namakkal-637 002, India

${ }^{2}$ Department of Chemistry, Chikkanna Government Arts College, Tirupur-641 602, India

${ }^{3}$ CIC Energigune, Energy Cooperative Research Centre, Parque Tecnologico, 01510 Minano (Alava), Spain

*Corresponding author: E-mail: environkarthi@gmail.com

\begin{abstract}
Magnetic metals Fe-Co encapsulated in multi-walled carbon nanotubes, were prepared by spray pyrolysis of methyl ester of Pongamia pinnata oil, a renewable carbon precursor, over Fe-Co catalyst supported on silica. Carbon nanostructures with different morphologies were obtained over Fe-Co catalyst supported on silica, with $20 \mathrm{~mL} / \mathrm{h}$ feed rate of precursor at different temperatures $(550,650$ and 750 ${ }^{\circ} \mathrm{C}$ ). The products were characterized by scanning electron microscopy, transmission electron microscopy, Raman spectroscopy, thermogravimetry and vibrating sample magnetometer. The Fe-Co encapsulated in multi-walled carbon nanotubes was used as adsorbent for removal of $\mathrm{As}(\mathrm{V})$ ions from aqueous solution. Sorption experiments were conducted using batch system. The effect of $\mathrm{pH}$ on $\mathrm{As}(\mathrm{V})$ ions adsorption on the adsorbent, effect of initial $\mathrm{As}(\mathrm{V})$ ions concentration on adsorption by adsorbent and effect of temperature on $\mathrm{As}(\mathrm{V})$ ions removal were studied. The kinetics of $\mathrm{As}(\mathrm{V})$ ions adsorption on Fe-Co encapsulated in multi-walled carbon nanotubes was discussed.
\end{abstract}

Keywords: Magnetic metal, Pongamia pinnata oil, Multi-walled carbon nanotubes, Spray pyrolysis method, Arsenic removal.

ᄂ - - - - - - - - - - - - - - - - - - - - - - - - - - -

\section{INTRODUCTION}

Magnetic nanoparticles are in the focus of research recently because of their attractive properties useful in catalysis ${ }^{1}$, biomedicine $^{2}$, magnetic resonance imaging ${ }^{3}$, magnetic particle imaging $^{4}$, data storage ${ }^{5}$ and environmental remediation ${ }^{6}$. The disadvantages of metallic nanoparticles are its lower stability in various chemical and physical environments such as acid or base media, as well as at high temperature and pressure. To access the much higher magnetic moments of magnetic nanoparticles and more stability, the magnetic core to be protected by surface coating that should be chemically inert towards air, acid and stable at elevated temperatures. The metallic core of magnetic nanoparticles may be passivated by gentle oxidation, surfactants, polymers and precious metals ${ }^{7}$. Nanoparticles with a magnetic core consisting either of $\mathrm{Fe}$ or $\mathrm{Co}$ with a non reactive shell made of graphene have been synthesized recently ${ }^{8}$. Enclosure of magnetic nanoparticles in graphite is of particular interest since it could prevent their degradation in reaction chemical environments and isolate the particles magnetically from each other to avoid low proximity interactions. In the recent past, various carbon-protected metal nanoparticles have been made by techniques including filling process, template- based synthesis, chemical vapour deposition, pyrolysis procedure, sol-gel process, self-assembly method etc. ${ }^{9}$. Many of these methods still suffer from various drawbacks such as complicated procedure and poor growth control of metal filled carbon nanotubes. Also, most of the encapsulated metals exist as particles or short rods and distribute randomly along the nanotubes ${ }^{10}$. Such a low filling efficiency limits the production of large amount of magnetic metal filled multi-walled carbon nanotubes for practical applications. Most of the carbon materials have been synthesized from precursors based on the fossil fuel like petroleum products ${ }^{11,12}$. Apart from expensiveness, these precursors will deplete at one point of time. It is therefore necessary to look for precursors which are plant based, renewable and environmentally safe. Recently, appreciable attempts were made for preparation of multiwalled carbon nanotubes and carbon encapsulated magnetic metal nanostructures from regenerative precursors ${ }^{13-16}$. Here in we report the results of experiments conducted to study the synthesis of Fe-Co magnetic metals encapsulated in multiwalled carbon nanotubes at different temperatures by spray pyrolysis of methyl ester of Pongamia pinnata oil over Fe-Co catalyst supported on silica in nitrogen atmosphere. The results show that ecologically advantageous and regenerative methyl 
ester of Pongamia pinnata oil may be an effective precursor for preparing magnetic metal encapsulated in MWCNTs by spray pyrolysis technique. Arsenic is considered as one of the most hazardous elements for living organisms and its presence in natural water can result in serious environmental problems. The possible application of Fe-Co encapsulated in MWCNTs as adsorbent for removal of $\mathrm{As}(\mathrm{V})$ ions from aqueous solutions were studied.

\section{EXPERIMENTAL}

A silica supported Fe-Co catalyst $\left(\mathrm{Fe}: \mathrm{Co}: \mathrm{SiO}_{2}=1: 0.6: 4\right)$ was prepared by wet impregnation method. ${ }^{17}$ Appropriate quantities of metal salts (Merck) i.e. $\mathrm{Fe}\left(\mathrm{NO}_{3}\right)_{3} \cdot 6 \mathrm{H}_{2} \mathrm{O}$ and $\mathrm{Co}\left(\mathrm{NO}_{3}\right)_{3} \cdot 3 \mathrm{H}_{2} \mathrm{O}$ were dissolved in methanol and mixed thoroughly with methanol suspension of silica (Merck). The solvent was then evaporated and the resultant cake heated to 90-100 ${ }^{\circ} \mathrm{C}$ for $3 \mathrm{~h}$, removed from the furnace and ground in an agate mortar. The fine powders were then calcined for $1 \mathrm{~h}$ at $450{ }^{\circ} \mathrm{C}$ and then re-ground before loading into the reactor. The prepared catalyst was directly placed in a quartz boat and kept at the centre of a quartz tube which was placed inside a tubular furnace. The carrier gas nitrogen was introduced at the rate of $100 \mathrm{~mL} / \mathrm{min}$ into the quartz tube to remove the presence of any oxygen inside the quartz tube. The temperature was raised from room temperature to the desired growing temperature. Subsequently, methyl ester of Pongamia pinnata oil was introduced into the quartz tube through spray nozzle and the flow was maintained at the rate of $0.5 \mathrm{~mL} / \mathrm{min}$. Spray pyrolysis was carried out for $45 \mathrm{~min}$ and thereafter furnace was cooled to room temperature. Nitrogen atmosphere was maintained throughout the experiment. The morphology and degree of graphitization of the as-grown nanostructures were characterized by scanning electron microscopy (Hitachi SU6600), high resolution transmission electron microscopy (JEOL3010), Raman spectroscopy (JASCO NRS-1500W, green laser with excitation wavelength $532 \mathrm{~nm}$ ) and thermogravimetric analysis (TGA). Magnetic properties of the sample at room temperature were studied using vibrating sample magnetometer. The as-grown products were subjected to purification process as follows ${ }^{18}$. The sample material was added to $5 \%$ HF solution to form acidic slurry. This slurry was heated to 60 ${ }^{\circ} \mathrm{C}$ and stirred at $600 \mathrm{rpm}$. The sample was filtered and washed with distilled water. The collected sample was dried at $120^{\circ} \mathrm{C}$ in air for $2 \mathrm{~h}$. The stock solution of $\mathrm{As}(\mathrm{V})$ was prepared by dissolving $\mathrm{Na}_{2} \mathrm{HAsO}_{4} .7 \mathrm{H}_{2} \mathrm{O}$ in distilled water. The residual $\mathrm{As}(\mathrm{V})$ concentration in solution after adsorption was analyzed using flame atomic adsorption spectrometer (AAS). The solution $\mathrm{pH}$ was adjusted with $\mathrm{HCl}$ and $\mathrm{NaOH}$.

\section{RESULTS AND DISCUSSION}

The yield, morphology and magnetic properties of asgrown products obtained from spray pyrolysis of methyl ester of Pongamia pinnata oil were studied. The carbon nanostructure yield at different temperatures viz., 550, 650 and $750{ }^{\circ} \mathrm{C}$ under constant precursor feed rate of $20 \mathrm{~mL} / \mathrm{h}$ over $\mathrm{Fe}-\mathrm{Co}$ catalyst supported on silica were shown in Fig. 1. A typical SEM and HRTEM image of samples synthesized at different reaction temperatures $\left(550,650\right.$ and $\left.750{ }^{\circ} \mathrm{C}\right)$ under constant precursor feed rate of $20 \mathrm{~mL} / \mathrm{h}$ were shown in Fig. 2. The $\mathrm{I}_{\mathrm{G}} / \mathrm{I}_{\mathrm{D}}$ values obtained from Raman spectral studies and the TGA result of carbon samples synthesized under constant precursor feed rate of $20 \mathrm{~mL} / \mathrm{h}$ for different temperatures were given in Table-1. The magnetic properties of purified sample of Fe-Co encapsulated in MWCNTs synthesized using methyl ester of Pongamia pinnata oil with a flow rate of $20 \mathrm{~mL} / \mathrm{h}$ at $650{ }^{\circ} \mathrm{C}$ was characterized by EDX and vibrating sample magnetometer (Fig. 3). Fe-Co encapsulated in MWCNTs as adsorbent for removal of $\mathrm{As}(\mathrm{V})$ ions from aqueous solutions were studied (Fig. 4).

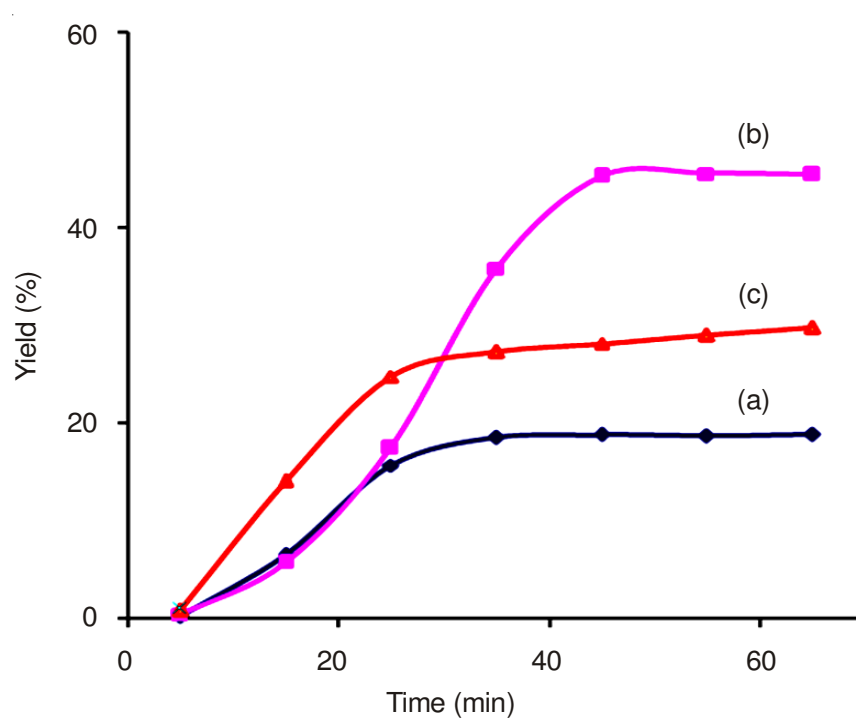

Fig. 1. Reaction time dependence of carbon yield under constant precursor feed rate of $20 \mathrm{~mL} / \mathrm{h}$ for different reaction temperatures (a) $550{ }^{\circ} \mathrm{C}$ (b) $650{ }^{\circ} \mathrm{C}$ (c) $750{ }^{\circ} \mathrm{C}$

TABLE-1

CHARACTERIZATION PARAMETERS: $\mathrm{I}_{\mathrm{G}} / \mathrm{I}_{\mathrm{D}}$ RATIO DETERMINED BY RAMAN STUDIES AND \% WEIGHT OF RESIDUE OBTAINED IN TGA FOR THE SAMPLES SYNTHESIZED AT DIFFERENT TEMPERATURES FOR THE PRECURSOR FLOW RATE OF $20 \mathrm{~mL} / \mathrm{h}$

\begin{tabular}{ccc}
$\begin{array}{c}\text { Temperature } \\
\left({ }^{\circ} \mathrm{C}\right)\end{array}$ & $\begin{array}{c}\mathrm{I}_{\mathrm{G}} / \mathrm{I}_{\mathrm{D}} \text { ratio } \\
(\text { Raman })\end{array}$ & $\begin{array}{c}\text { \% Weight of residue in TGA } \\
\text { for the purified sample }\end{array}$ \\
\hline 550 & 0.53 & 8.6 \\
650 & 0.94 & 21.9 \\
750 & 1.42 & 5.7 \\
\hline
\end{tabular}

The influence of temperature on carbon yield shows low yield at $550{ }^{\circ} \mathrm{C}$ (Fig. 1a). This may be due to low catalytic activity of catalyst at this temperature. At reaction temperature $650{ }^{\circ} \mathrm{C}$, the increased yield of MWCNTs at early stage of reaction is due to the high catalytic activity of the catalyst (Fig. 1b). However, the low yield of MWCNTs obtained, as shown in Fig. 1c, at high temperature range $\left(750^{\circ} \mathrm{C}\right)$ compare to yield of MWCNTs at $650{ }^{\circ} \mathrm{C}$ may be due to deactivation of catalyst particles by the encapsulation of graphitic carbon. The fact can be referred to the report by Kang et al. ${ }^{19}$ that at high synthesis temperature, the rate of carbon nucleation was too fast compared to that of precipitation resulting in a rapid encapsulation of the catalyst particles by graphitic carbon.

The SEM observations of the sample synthesized at reaction temperature $550{ }^{\circ} \mathrm{C}$ show less densely populated and large diameter carbon nanotubes (Fig. 2a). The poor crystallization 

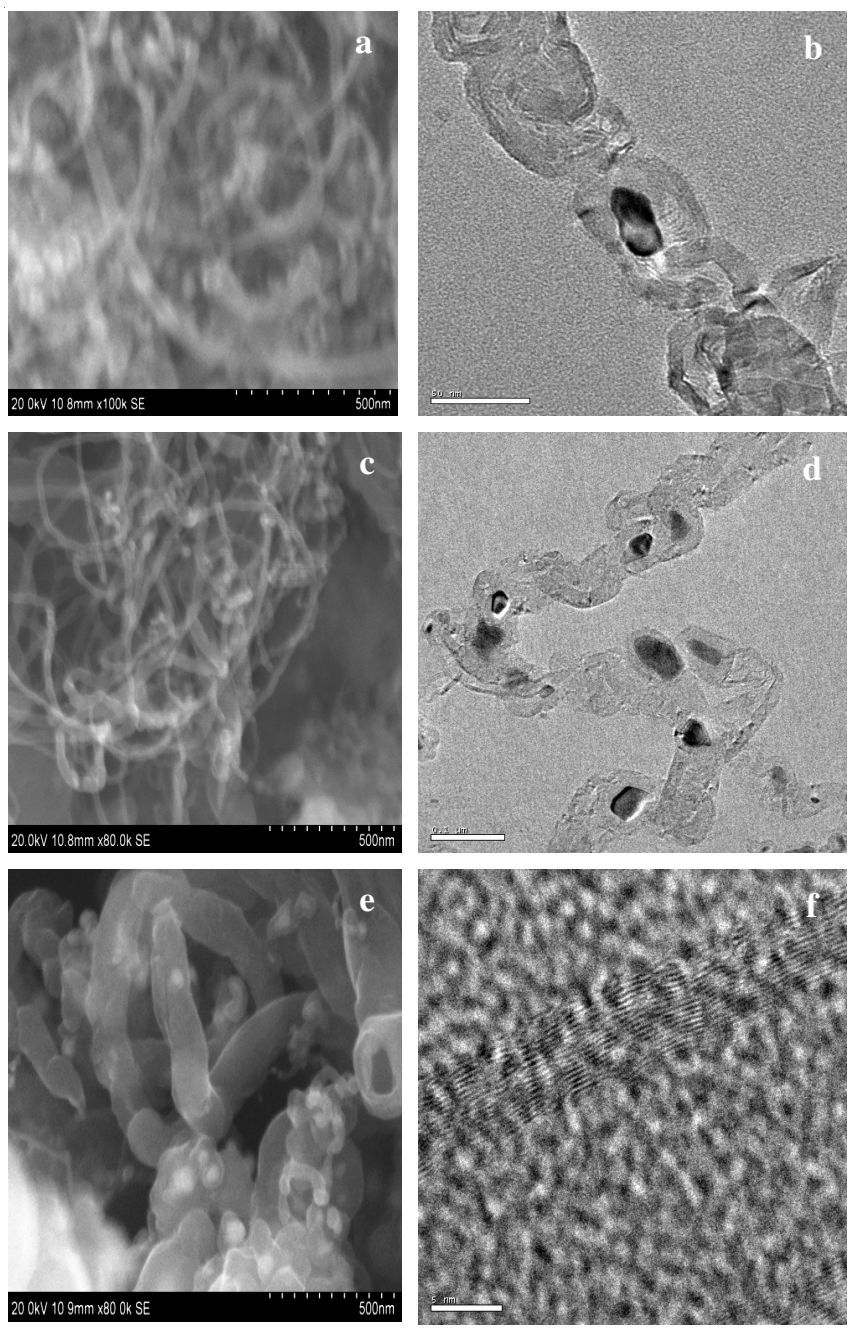

Fig. 2. A typical SEM and HRTEM image of samples synthesized at different reaction temperatures under constant precursor feed rate of $20 \mathrm{~mL} / \mathrm{h} \mathrm{SEM}$ : (a) $550{ }^{\circ} \mathrm{C}$ (c) $650{ }^{\circ} \mathrm{C}$ (e) $750{ }^{\circ} \mathrm{C}$ and HRTEM: (b) $550{ }^{\circ} \mathrm{C}$ (d) $650{ }^{\circ} \mathrm{C}$ (f) $750{ }^{\circ} \mathrm{C}$

of carbon layers were evident from the HRTEM image of the sample synthesized at $550{ }^{\circ} \mathrm{C}$ (Fig. 2b). The SEM image of the sample synthesized at $650{ }^{\circ} \mathrm{C}$ shows densely formed carbon nanotubes (Fig. 2c). The HRTEM of the sample synthesized at $650{ }^{\circ} \mathrm{C}$ (Fig. 2d) indicate the metal particles, seen as a dark spot, were tightly covered by carbon layers with a thickness of a few nanometers and graphitic layers surrounding the
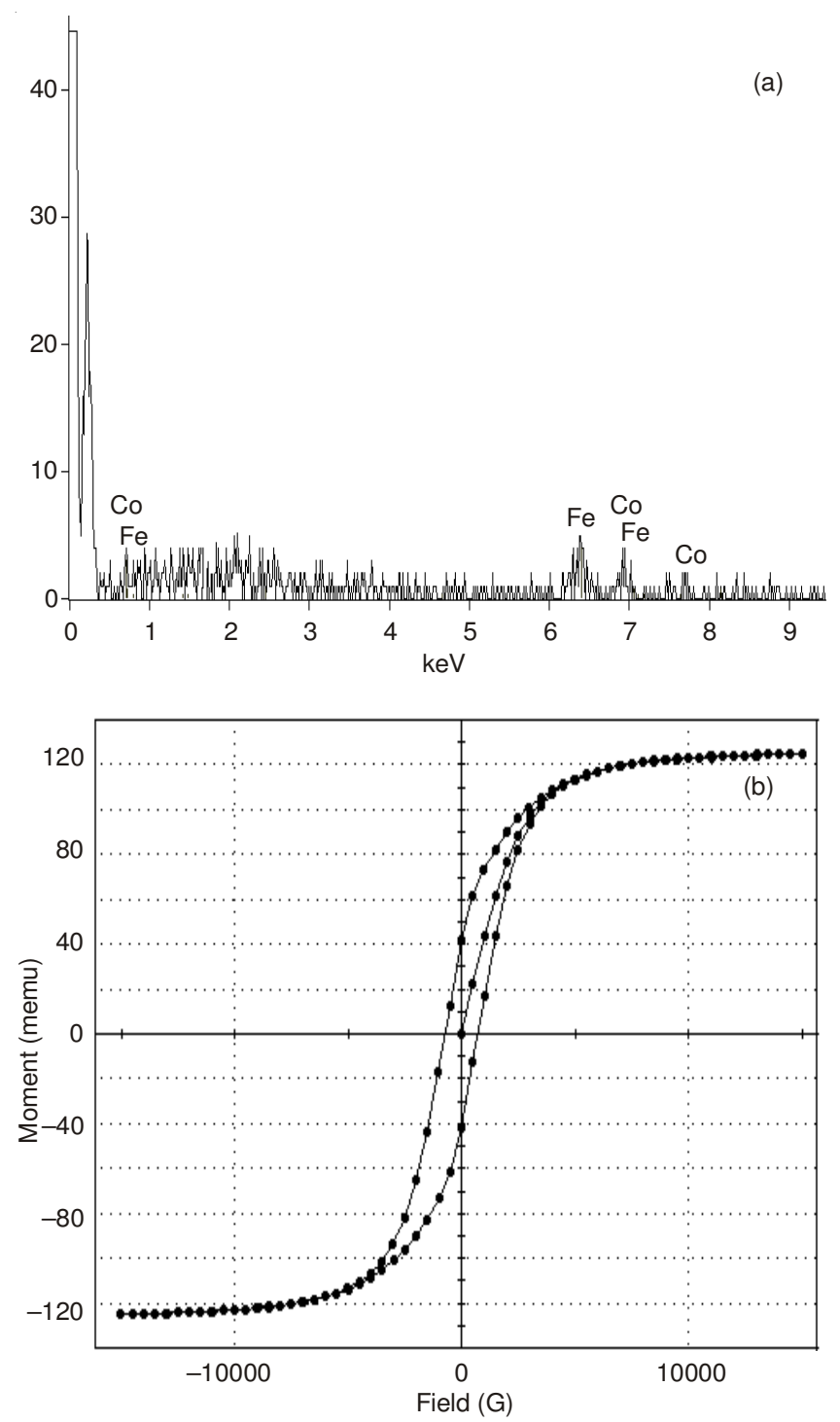

Fig. 3. Fe-Co encapsulated in MWNTs sample synthesized at $650{ }^{\circ} \mathrm{C}$ (a) EDX result; (b) Hysteresis loops ( $\mathrm{M}$ vs. $\mathrm{H})$ recorded

catalyst particles were with good crystallinity. The SEM image (Fig. 2e) of the sample synthesized at $750{ }^{\circ} \mathrm{C}$ indicates that the carbon nanotubes formed were thick in size. The sample contains less densely populated MWCNTs along with amorphous carbon. However, The HRTEM image (Fig. 2f) of
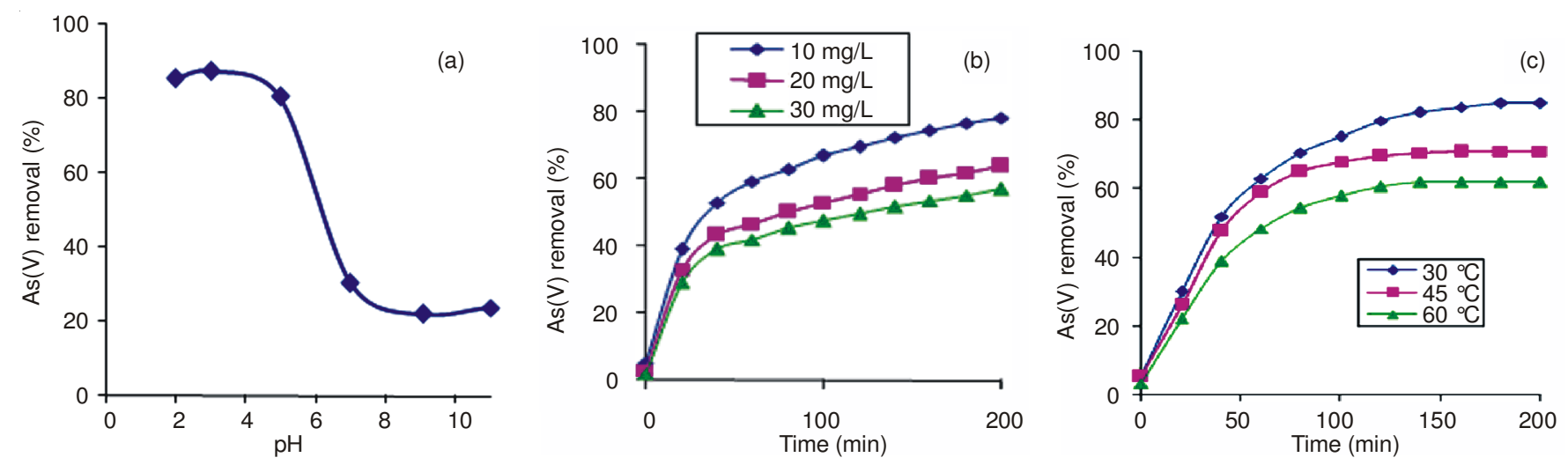

Fig. 4. (a) Effect of $\mathrm{pH}$ on $\mathrm{As}(\mathrm{V})$ ion adsorption on Fe-Co encapsulated in MWNTs; (b) Effect of initial As(V) ion concentration on adsorption by Fe-Co encapsulated in MWNTs; (c) Effect of temperature on $\mathrm{As}(\mathrm{V})$ ion removal 
the MWCNTs formed at a reaction temperature $750{ }^{\circ} \mathrm{C}$ evidenced good crystalline graphitic layers of MWCNTs.

The crystallinity of MWCNTs was characterized by Raman scattering studies. The $\mathrm{G}$ band at $1578 \mathrm{~cm}^{-1}$ is attributed to crystalline carbon layers. The D band at $1343 \mathrm{~cm}^{-1}$ is associated with the defects, vacancies and impurities that destroy the graphitic layer symmetry ${ }^{20,21}$. The intensity ratio of G-band and D-band $\left(\mathrm{I}_{\mathrm{G}} / \mathrm{I}_{\mathrm{D}}\right)$ obtained from Raman scattering spectral values for the MWCNTs synthesized at different temperatures were shown in Table- 1 . The poor quality of carbon layer formed for the sample synthesized at $550{ }^{\circ} \mathrm{C}$ was evident from the $\mathrm{I}_{\mathrm{G}} / \mathrm{I}_{\mathrm{D}}$ value of 0.53 and the fact was supported by HRTEM images (Fig. 2b). The $\mathrm{I}_{\mathrm{G}} / \mathrm{I}_{\mathrm{D}}$ value of 0.94 (Table-1) for samples prepared at $650{ }^{\circ} \mathrm{C}$ with flow rate of $20 \mathrm{~mL} / \mathrm{h}$ indicates that magnetic nanoparticals encapsulated in carbon nanotubes structure had defects and moderate crystallization of graphene planes. The $\mathrm{I}_{\mathrm{G}} / \mathrm{I}_{\mathrm{D}}$ (Table-1) value 1.42 for the samples synthesized at $750{ }^{\circ} \mathrm{C}$ indicate the formation of MWCNTs with good crystalline graphitic layers.

The as-grown samples consists of support material silica, the metals $\mathrm{Fe}$ and $\mathrm{Co}$ used as catalyst, Fe-Co encapsulated in MWCNTs, amorphous carbon and carbon nanostructures. The process of purification removes the support material silica and un-encapsulated $\mathrm{Fe}$ and $\mathrm{Co}$. The TGA results of purified samples were shown in Table-1. The weight of residue was 8.6, 21.9 and $5.7 \%$ mass fraction for the purified samples synthesized at 550,650 and $750{ }^{\circ} \mathrm{C}$ respectively. The low percentage weight of residue observed for the products synthesized at $550{ }^{\circ} \mathrm{C}$ and $750{ }^{\circ} \mathrm{C}$ were attributed to acid leaching of support and catalyst particles that were not encapsulated by carbon. The carbon sample synthesized at $650{ }^{\circ} \mathrm{C}$ with a precursor feed rate of $20 \mathrm{~mL} / \mathrm{h}$ after purification process shows $21.9 \%$ weight of residue in TGA studies. The high value of residue obtained in TGA for the purified sample is attributed to the fact that carbon layers covering the metal particles prevent the dissolution of metal during purification. This indicates effective formation of $\mathrm{Fe}-\mathrm{Co}$ nanoparticles encapsulated in MWCNTs at $650{ }^{\circ} \mathrm{C}$ for $20 \mathrm{~mL} / \mathrm{h}$ precursor flow rate compared to other experimental conditions employed in this study.

The magnetic hysteresis loops (Fig. 3b), for the purified sample synthesized using methyl ester of Pongamia pinnata oil with a flow rate of $20 \mathrm{~mL} / \mathrm{h}$ at $650{ }^{\circ} \mathrm{C}$, shows the ferromagnetic behaviour of $\mathrm{Fe}-\mathrm{Co}$ encapsulated in MWCNTs. The saturation magnetization for the sample was $6 \mathrm{emu} / \mathrm{g}$. The coercivity of the sample was $721.45 \mathrm{G}$. The results confirmed the successful encapsulation of Fe-Co in MWCNTs. The encapsulation of Fe-Co in MWCNTs was also evidenced by EDX (Fig. 3a) for the sample. The hysteresis loops for the sample are the typical loops of soft magnet. The saturation magnetization value of Fe-Co encapsulated in MWCNTs is comparable with the reported values ${ }^{22}$.
The perspectives of Fe-Co encapsulated in MWCNTs in environmental treatment are outlined with study of adsorption of arsenate $[\mathrm{As}(\mathrm{V})]$ ions on the purified Fe-Co encapsulated in MWCNTs. The adsorption of arsenic from aqueous solution using MWCNTs was found to be highly $\mathrm{pH}$ dependent process. The effect of $\mathrm{pH}$ on the adsorption process is mainly influenced by the two factors: (i) distribution of arsenate ion species $[\mathrm{As}(\mathrm{V})]$ in the solution phase and (ii) the surface charge of the adsorbent. Therefore, the interaction between $\mathrm{As}(\mathrm{V})$ ion and MWCNTs is basically a combined result of charges on the $\mathrm{As}(\mathrm{V})$ ion and MWCNTs. The effect of $\mathrm{pH}$ for the adsorption of $\mathrm{As}(\mathrm{V})$ ion on MWCNTs over a $\mathrm{pH}$ range of 2 to 11 is presented in Fig. 4a. It is evident from the Fig. 4a that high percentage $\mathrm{As}(\mathrm{V})$ ion adsorption on MWCNTs occurs at $\mathrm{pH}$ value of 2 . The percentage adsorption of $\mathrm{As}(\mathrm{V})$ ion decreases rapidly to a low value at $\mathrm{pH} 7$ and remain almost constant for increase of $\mathrm{pH}$ up to 11. In an aqueous solution, in the $\mathrm{pH}$ range of 2 to 11 , the $\mathrm{As}(\mathrm{V})$ ion exist as $\mathrm{H}_{2} \mathrm{AsO}_{4}{ }^{-}, \mathrm{HAsO}_{4}{ }^{2-}$ and $\mathrm{AsO}_{4}{ }^{3-}$ ions ${ }^{23}$. The isoelectric point value of 5.8 for MWCNTs indicate that the surface of MWCNTs is positively charged under acidic conditions and these positive charges facilitate the removal of $\mathrm{As}(\mathrm{V})$ ions. At higher $\mathrm{pH}$ value the adsorption of $\mathrm{As}(\mathrm{V})$ ion on MWCNTs decreases due to the electrostatic repulsion between the ionized MWCNTs and the As(V) ion. However, small amount of adsorption observed may be attributed to physicochemical adsorption of $\mathrm{As}(\mathrm{V})$ ion over the surface of MWCNTs. The effect of initial As(V) ions concentration and contact time for the removal of $\mathrm{As}(\mathrm{V})$ ions by MWCNTs were shown in Fig. 4b. In this study 10, 20 and $30 \mathrm{mg} / \mathrm{L} \mathrm{As}(\mathrm{V})$ ion concentrated solutions were used. Fig. 4b shows that As(V) ions adsorption depends on initial concentration of $\mathrm{As}(\mathrm{V})$ ion. Rapid removal of $\mathrm{As}(\mathrm{V})$ ions were noticed during the initial $0.5 \mathrm{~h}$ of contact time and reaches the equilibrium around $2 \mathrm{~h}$ for all range of concentrations studied. Decrease in adsorption percentage at higher concentrations might be due to the relatively smaller number of active sites available at higher $\mathrm{As}(\mathrm{V})$ ions concentration. The kinetics of $\mathrm{As}(\mathrm{V})$ ions adsorption on MWCNTs were determined for initial As(V) ions concentration $20 \mathrm{mg} / \mathrm{L}$, pH value of 4, MWCNTs dose $1 \mathrm{~g} / \mathrm{L}$ at different temperatures viz. 30, 45 and $60{ }^{\circ} \mathrm{C}$. The analyses of results are shown in Table-2. Pseudo second order equation provided a best fit description for the adsorption of $\mathrm{As}(\mathrm{V})$ ions on to chosen MWCNTs relative to Elovich and pseudo first order equations ${ }^{24-26}$.

\section{Conclusion}

A green synthesis of magnetic metal encapsulated in multiwalled carbon nanotubes by spray pyrolysis of methyl ester of Pongamia pinnata oil, an eco-friendly natural precursor using $\mathrm{Fe}-\mathrm{Co}$ catalyst supported on silica was demonstrated.

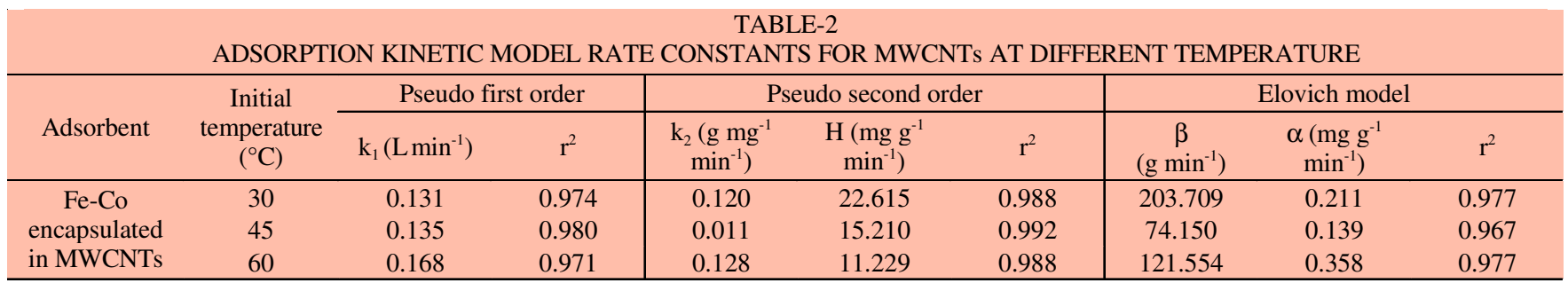


The optimum reaction conditions for synthesis of magnetic metal encapsulated in multi-walled carbon nanotubes were $650{ }^{\circ} \mathrm{C}$ and the precursor flow rate of $20 \mathrm{~mL} / \mathrm{h}$. The removal of $\mathrm{As}(\mathrm{V})$ ions from aqueous solution was possible using Fe-Co encapsulated in MWCNTs. The adsorption of As(V) ions was found to be dependent on $\mathrm{pH}$, temperature and concentration of adsorbent. The percentage saturation was found to be almost $75 \%$. The kinetics of $\mathrm{As}(\mathrm{V})$ ions adsorption on Fe-Co encapsulated in MWCNTs adsorbent was found to follow a pseudo second-order rate equation.

\section{ACKNOWLEDGEMENTS}

The authors thank UGC, New Delhi for financial support (UGC Major Grant), IITM and The Institute for Environmental Nanotechnology for their technical support.

\section{REFERENCES}

1. A.H. Lu, W. Schmidt, N. Matoussevitch, H. Bonnemann, B. Spliethoff, B. Tesche, E. Bill, W. Kiefer and F. Schith, Angew Chem. Int. Ed., 43, 4303 (2004).

2. A.K. Gupta and M. Gupta, Biomaterials, 26, 3995 (2005).

3. S. Mornet, S. Vasseur, F. Grasset, P. Veverka, G. Goglio, A. Demourgues, I. Portier, E. Pollert and E. Duguet, Pro. Solid State Chem. 34, 237 (2006).

4. B. Gleich and J. Weizenecker, Nature, 435, 214 (2005).

5. T. Hyeon, Chem. Commun., 8, 927 (2003).

6. D.W. Elliott and W.X. Zhang, Environ. Sci. Technol., 35, 4922 (2001).

7. A.H. Lu, E.L. Salabas and F. Schuth, Angew Chem. Int. Ed., 46, 1222 (2007).
8. R.N. Grass and W.J. Stark, J. Mater. Chem., 16, 1825 (2006).

9. M. Zhu and G. Diao, Nanoscale, 3, 2748 (2011).

10. N. Grobert, M. Mayne, M. Terrones, J. Sloan, R.E. Dubin-Borkowski, R. Kamalakaran, T. Seeger, H. Terrones, M. Ruhle, D.R.M. Walton, H.W. Kroto and J.L. Hutchison, Chem. Commun., 5, 471 (2001).

11. S. Karthikeyan, P. Mahalingam and M. Karthik, E-J. Chem., 6, 1 (2009).

12. A.L. Mohann Reddy and S. Ramaprabhu, Nanoscale Res. Lett., 3, 76 (2008).

13. S. Karthikeyan and P. Mahalingam, Int. J. Nanotechnol. Appl., 4, 189 (2010).

14. E.F. Antunes, V.G. de Resende, U.A. Nengui, J.B.M. Cunha, E.J. Corat and M. Massi, Appl. Surf. Sci., 257, 8038 (2011).

15. L. Jian-hua, H. Ruo-yu, L. Guo-hua, Z. Ying, L. Hong-Zhong and W. Dong-guang, New Carbon Mater, 25, 192 (2010).

16. S. Karthikeyan and P. Mahalingam, Int. J. Green Nanotechnol. Phys. Chem., 2, 39 (2010).

17. S.D. Mhlanga, C.M. Kartick, C. Robin, M.J. Witcomb and N.J. Coville, S. Afr. J. Chem., 62, 67 (2009).

18. R. Engel-Herbert, H. Pforte and T. Hesjedal, Mater. Lett., 61, 2589 (2007).

19. J.L. Kang, J.J. Li, X.W. Du, C.S. Shi, N.Q. Zhao, L. Cui and P. Nash, J. Alloys Compd., 456, 290 )2008).

20. M.S. Dresselhaus, G. Dresselhaus, A. Jorio, A.G. Souza Filho and R. Saito, Carbon, 40, 2043 (2002).

21. T. Belin and F. Epron, Mater. Sci. Eng. B, 119, 105 (2005).

22. L.S. Panchakarla and A. Govindaraj, Bull. Mater. Sci., 30, 23 (2007).

23. S.S. Tripathy and A.M. Raichur, Chem. Eng. J., 138, 179 (2008).

24. S.H. Chein and W.R. Clayton, Soil Sci. Soc. Am. J., 44, 265 (1980).

25. S. Karthikeyan, G. Bhuwaneshwari, S. Malathi and P. Maheswari, J. Indian Coun. Chem., 24, 63 (2007).

26. S. Karthikeyan, M. Jambulingam and P. Sivakumar, Res. J. Chem. Environ., 10, 72 (2006) 